ORIGINAL ARTICLE

\title{
Toxicity of AgNPs upon Liver Function and Positive Role of Tinospora Cordifolia: In Vivo
}

\author{
SAMED ABDUL JABBAR RAMADHAN ${ }^{1}$, OZDAN AKRAM GHAREEB ${ }^{2}$ \\ ${ }^{1}$ Department of Healthy Nutrition Techniques, Medical Technology-Baghdad Institute, Middle Technical University, Iraq \\ ${ }^{2}$ Department of Community Health Techniques, Kirkuk Technical Institute, Northern Technical University, Iraq.
}

\begin{abstract}
This experiment was premeditated to probe the toxic impact of Silver Nanoparticles (AgNPs) upon liver function parameters in male rats, as well as to demonstrate the protective effect of Tinospora cordifolia (T.C) against liver function disorders caused by AgNPs. Twenty-four rats were classified into four packs, six ones for every pack. Rats were included by control animals without treatment, while the AgNPs group included rats treated with $50 \mu \mathrm{l} / \mathrm{kg} /$ day AgNPs. In the AgNPs + T.C group, rats were co-administered of AgNPs at a dose of $50 \mu \mathrm{l} / \mathrm{kg}$ with T.C at a dose of $400 \mathrm{mg} / \mathrm{kg}$. Whereas, animals of the T.C pack were treated with $400 \mathrm{mg} / \mathrm{kg}$ of T.C. The duration of the experiment was 28 days. After blood samples were taken at the conclusion of the experiment. The levels of biochemical parameters (liver enzymes) such as alanine aminotransferase, aspartate aminotransferase, and alkaline phosphatase were evaluated to detect liver function abnormalities. The results showed that AgNPs induced a significant increase in the activity of serum liver enzymes in comparison to the control group ( $p<$ 0.05).While T. cordifolia co-treatment significantly reduced the levels of activities of those enzymes. Therefore, it can be considered that T. cordifolia effectively contributes to the protection against liver dysfunction caused by AgNPs in rats.
\end{abstract}

Keywords : Silver Nanoparticles, liver dysfunction, biochemical parameters.

\section{INTRODUCTION}

Nanotechnology and its application in medicine have revolutionized healthcare (1). It has the ability to improve some medical diagnosis as well as treat and prevent some diseases ${ }^{(2,3)}$. Among the metallic nanoparticles, silver nanoparticles (AgNPs) have antimicrobial, catalytic and other properties, which make it possible to be applied in medicine and pharmaceutical industry (4-6). On the other hand, many studies have revealed the presence of toxic effects of nanoparticles in vivo (7). There is a special modern scientific branch that aims to study the potential negative effects of nanoparticles and related parameters affecting the cytotoxicity of nanomaterial's called nanotoxicology $(8,9)$. To this day, herbs are mainly used as treatment in many developing countries for primary health care due to their acceptability in the human body as well as their fewer side effects $(10,11)$. Tinospora cordifolia, which belongs to the Menispermaceae family, is a herbal plant that is used in many traditional medicinal fields to treat various diseases. Botanical components rich in bioactivity make this plant a vital role in expressing a wide range of beneficial effects in metabolic disorders $(12,13)$. The present paper aims at confirming the toxic influence of silver nanoparticles upon the biochemical parameters of the liver and at evaluating the potential protective role of $\mathrm{T}$. cordifolia against these harmful effects.

\section{METHODS}

Chemicals: Silver (Ag) Nanoparticle Water Dispersion was supplied by US Research Nano-material, Inc. (Houston, TX, USA).Product No.: US 7140. Average particle size (APS): $15 \mathrm{~nm}, \mathrm{Ag}$ concentration: 1000 ppm. Particle Purity: 99.9\%, Crystal Type: Spherical. As for T.Cordifolia (plant supplement), it was obtained from Guduchi/Giloy Pure Extract Capsules, ( Nature's Velvet Life Care, India).

Animals \& Experimental Design: This experiment was conducted on (24) adult male rats, their ages ranged between 5-6 months, and their weights were 195-225 g. Animals were supplied from the laboratory animal centers, and housed in plastic cages and under typical conditions at $25 \pm 2{ }^{\circ} \mathrm{C}$ and $12 \mathrm{~h}$ light-dark cycles. They are permissible for accessing feed and water. These rats were haphazardly classified into 4 packs, and in every single pack 6 rats were as follows:

Controlling group (CON): Healthy rats, which did not receive any treatments.

Group (AgNPs): Rats were given silver nanoparticles at a dose of $50 \mu \mathrm{l} / \mathrm{kg} /$ day intraperitoneally ${ }^{(14)}$.

Group (AgNPs + T.C): rats were co-administered of silver nanoparticles $(50 \mu \mathrm{l} / \mathrm{kg} /$ day IP) with T.Cordifolia at $400 \mathrm{mg} / \mathrm{kg}$ dose ${ }^{(15)}$ orally by gavage tube .

- $\quad$ Group IV (T.C): T.Cordifolia was taken at 400 mg/kg dose alone.

After the experiment period (28 days), the rats were euthanized then sacrificed, and a heart puncture was used to draw blood. Tubes were used to collect blood samples that did not contain anticoagulants for biochemical testing.

Biochemical Analyzes: Roche diagnostic kits were used to calculate serum alanine aminotransferase (ALT), aspartate aminotransferase (AST), and alkaline phosphatase (ALP) in an automated system.

Statistic Assay: The statistics for this study were stated as the standard deviation $( \pm)$ SD $(n=6)$. All variance parameters amongst groups were investigated employing one-way assay of variance (ANOVA) trailed by Duncan. A significant difference was considered at $<0.05 P$ value.

\section{RESULTS}

Fig. (1) illustrates the results of the experimental groups for the current study. Rats that took AgNPs showed higher levels of liver enzymes ALT, ALP and AST in comparison to those within the controlling group. The results also revealed no noteworthy change in all three liver biochemical parameters in animals with co-administration 
of T. Cordifolia extract when compared with AgNPs treated mice $(P<0.05)$. This indicates that the liver could be slightly damaged with AgNPs administration, and that liver function was affected by AgNPs. But there was no obvious damage when the rats were dosed with T. Cordifolia.
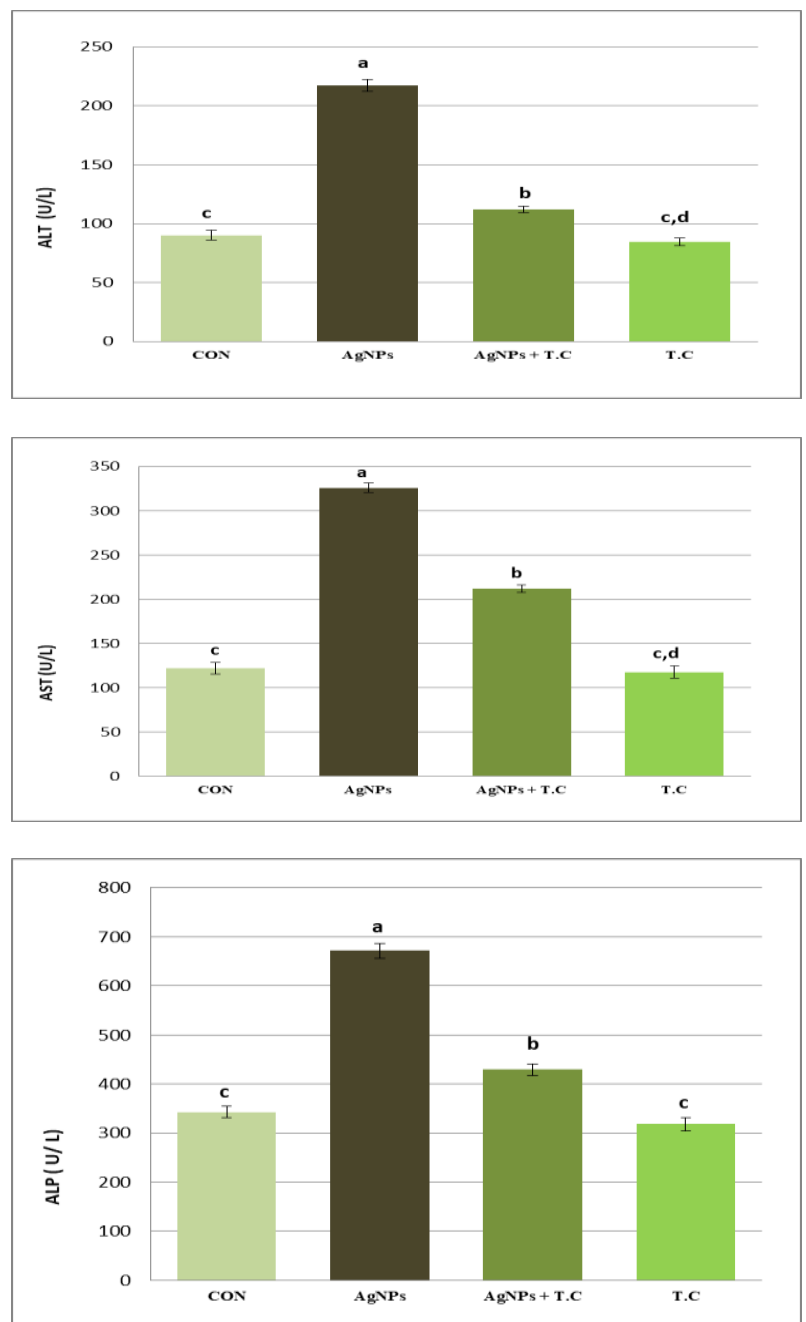

Figure 1: Results of liver function parameters: (a) ALT, (b) AST, and (c) ALP for the study groups. The data were expressed as mean $\pm S D$. ${ }^{a-d}$ Different superscripts indicate significant intracolumn differences $(p<0.05)$.

\section{DISCUSSION}

Investigation of the nano-toxic effects of AgNPs is important for many areas of its use such as pharmaceutical applications and food packaging processes, which makes it a desirable material for humanity $(16,17)$. The toxicity of NPs is due to special chemical and physical properties such as size, surface chemical modification and ion release (18) .Previous in vivo studies indicated that different types of nanoparticles tend to settle down in the liver with different toxic effects. The liver is the primary organ responsible for removing toxins from the body ${ }^{(19,20)}$. In this study, clinical biochemical analysis of body fluids was carried out for detecting the toxic impacts of these nanoparticles on liver function (21). In this experimental study, it was found that AgNPs negatively affected the enzymatic parameters of liver function, which was consistent with previous studies (22-24). Where disturbances in the levels of biochemical parameters in the serum indicate the unhealthy and pathological state of the liver. Elevated levels of serum of AST, ALT, and ALP, produced by damaged hepatocytes in the circulation, are associated with serious liver dysfunction $(25,26)$. These hepatic parameters showed moderation in the AgNPs + T.cordifolia group when compared to the AgNPs group. This can be attributed to the phytochemical components of the extract because it contains alkaloids, glycosides, sesquiterpenoids, lactones, and steroids ${ }^{(27-29)}$. On the other hand, it was found that T. cordifolia extract had a good liver protective effect on male rats against the toxicity caused by gold nanoparticles. Where doses of this plant extract were given orally and prevented damage to hepatocytes ${ }^{(30)}$.

\section{CONCLUSIONS}

Silver nanoparticles, according to the results of the current study, have a detrimental effect on liver function. While $\mathrm{T}$. cordifolia significantly reduced the high levels of serum enzymes associated with the liver.

\section{REFERENCES}

1- $\quad$ Sreenilayam SP, Ahad IU, Nicolosi V, Brabazon D. Mxene materials based printed flexible devices for healthcare, biomedical and energy storage applications. Materials Today. 2021 Feb 5.

2- Augustine R, Al Mamun A, Hasan A, Salam SA, Chandrasekaran R, Ahmed R, Thakor AS. Imaging cancer cells with nanostructures: Prospects of nanotechnology driven non-invasive cancer diagnosis. Advances in Colloid and Interface Science. 2021 Jun 3:102457.

3- $\quad$ Singh YD, Ningthoujam R, Panda MK, Jena B, Babu PJ, Mishra AK. Insight from Nanomaterials and Nanotechnology towards covid-19. Sensors International. 2021 May 13:100099.

4- Naghizadeh A, Mizwari ZM, Ghoreishi SM, Lashgari S, Mortazavi-Derazkola S, Rezaie B. Biogenic and eco-benign synthesis of silver nanoparticles using jujube core extract and its performance in catalytic and pharmaceutical applications: Removal of industrial contaminants and in-vitro antibacterial and anticancer activities. Environmental Technology \& Innovation. 2021 Aug 1;23:101560.

5- Ghareeb OA, Sulaiman RR, Ibrahim SH. Impact of Silver Nanoparticles on Hematological Profiles and Hepatorenal Functions in Photosensitivity: In Vivo. Annals of the Romanian Society for Cell Biology. 2021 Apr 19:7448-59.

6- Shirzadi-Ahodashti M, Mizwari ZM, Hashemi Z, Rajabalipour S, Ghoreishi SM, Mortazavi-Derazkola S, Ebrahimzadeh MA. Discovery of high antibacterial and catalytic activities of biosynthesized silver nanoparticles using $\mathrm{C}$. fruticosus (CFAgNPs) against multi-drug resistant clinical strains and hazardous pollutants. Environmental Technology \& Innovation. 2021 Aug 1;23:101607.

7- Ramadhan SA, Ghareeb OA. Clinicohematological Study of Gold Nanoparticles Toxicity and Ameliorative Effect of Allium Sativum. Annals of the Romanian Society for Cell Biology. 2021 Jan 31:597-602.

8- $\quad$ Pimtong W, Samutrtai P, Wongwanakul R, Aueviriyavit S. Predictive models for nanotoxicology: in vitro, in vivo, and computational models. InHandbook of Nanotechnology Applications 2021 Jan 1 (pp. 683-710). Elsevier.

9- Ghareeb OA. Toxicopathological Effects of Zinc Oxide Nanoparticles on the Liver Function and Preventive Role of 
Silymarin In vivo. Indian Journal of Forensic Medicine \& Toxicology. 2021 Apr;15(2):3213.

10- Al-Haidari KAA, Faiq TN, Ghareeb OA. Preventive value of black seed in people at risk of infection with COVID - 19. Pakistan Journal of Medical and Health Sciences. 2021 Jan $1 ; 15(1)$.

11- Ghareeb OA, Ramadhan SA. COVID 19-a novel zoonotic disease: Origin, prevention and control. Pakistan Journal of Medical and Health Sciences. 2021 Jan 1;15(1).

12- Sharma P, Dwivedee BP, Bisht D, Dash AK, Kumar D. The chemical constituents and diverse pharmacological importance of Tinospora cordifolia. Heliyon. 2019 Sep 1;5(9):e02437.

13- Singh RS, Singh A, Kaur $H$, Batra G, Sarma $P$, Kaur $H$, Bhattacharyya A, Sharma AR, Kumar S, Upadhyay S, Tiwari V. Promising traditional Indian medicinal plants for the management of novel Coronavirus disease: A systematic review. Phytotherapy Research. 2021 Jun 16.

14- Ghareeb OA. Toxic Effect of Silver Nanoparticles on Some Hematological Parameters and Possible Preventive Role of Moringa Oleifera: In Vivo. Annals of the Romanian Society for Cell Biology. 2021 May 3:13796-801.

15- Sharma V, Pandey D. Protective role of Tinospora cordifolia against lead-induced hepatotoxicity. Toxicology international. 2010 Jan;17(1):12.

16- Jamil B, Javed R, Qazi AS, Syed MA. Nanomaterials: Toxicity, Risk Managment and Public Perception. InNanomaterials: Ecotoxicity, Safety, and Public Perception 2018 (pp. 283-304). Springer, Cham.

17- Ahari $H$. The Use of Innovative Nano emulsions and NanoSilver Composites Packaging for anti-bacterial properties: An article review. Iranian Journal of Aquatic Animal Health. 2017 Apr 10;3(1):61-73

18- Pan B, Xing B. Applications and implications of manufactured nanoparticles in soils: a review. European Journal of Soil Science. 2012 Aug;63(4):437-56.

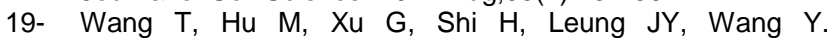
Microplastic accumulation via trophic transfer: Can a predatory crab counter the adverse effects of microplastics by body defence?. Science of The Total Environment. 2021 Feb 1;754:142099.

20- Mazumder K, Sumi TS, Golder M, Biswas B, Kerr PG. Antidiabetic profiling, cytotoxicity and acute toxicity evaluation of aerial parts of Phragmites karka (Retz.). Journal of Ethnopharmacology. 2021 Apr 24;270:113781.

21- Arika WM, Nyamai DW, Musila MN, Ngugi MP, Njagi EN. Hematological markers of in vivo toxicity. Journal of Hematology \& Thromboembolic Diseases. 2016 Mar 29.

22- Renuka RR, Ravindranath RR, Raguraman V, Yoganandham ST, Kasivelu G, Lakshminarayanan A. In
Vivo Toxicity Assessment of Laminarin Based Silver Nanoparticles from Turbinaria ornata in Adult Zebrafish (Danio rerio). Journal of Cluster Science. 2020 Jan;31(1):185-95.

23- Veisi S, Sarkheil M, Johari SA, Safari O. Dietary supplementation with melatonin: influence on growth performance, oxidative stress status, and amelioration of silver nanoparticles-induced toxicity in Nile tilapia (Oreochromis niloticus). Tropical Animal Health and Production. 2021 Jun;53(2):1-3.

24- Seyedi J, Tayemeh MB, Esmaeilbeigi M, Joo HS, Langeroudi EK, Banan A, Johari SA, Jami MJ. Fatty acid alteration in liver, brain, muscle, and oocyte of zebrafish (Danio rerio) exposed to silver nanoparticles and mitigating influence of quercetin-supplemented diet. Environmental Research. 2021 Mar 1;194:110611.

25- Yang L, Cao H, Sun D, Hou B, Lin L, Shen ZY, Song HL. Bone marrow mesenchymal stem cells combine with normothermic machine perfusion to improve rat donor liver quality-the important role of hepatic microcirculation in donation after circulatory death. Cell and tissue research. 2020 Aug;381(2):239-54.

26- Teksoy O, Sahinturk V, Cengiz M, İnal B, Ayhancı A. The protective effects of silymarin on thioacetamide-induced liver damage: measurement of miR-122, miR-192, and miR-194 levels. Applied biochemistry and biotechnology. 2020 Jun;191(2):528-39.

27- Saeed M, Naveed M, Leskovec J, Kakar I, Ullah K, Ahmad F, Sharif M, Javaid A, Rauf M, Abd El-Hack ME, Abdel-Latif MA. Using Guduchi (Tinospora cordifolia) as an eco-friendly feed supplement in human and poultry nutrition. Poultry science. 2020 Feb 1;99(2):801-11.

28- Patil S, Ashi H, Hosmani J, Almalki AY, Alhazmi YA, Mushtaq S, Parveen S, Baeshen HA, Varadarajan S, Raj AT, Patil VR. Tinospora cordifolia (Thunb.) Miers (Giloy) inhibits oral cancer cells in a dose-dependent manner by inducing apoptosis and attenuating epithelial-mesenchymal transition. Saudi Journal of Biological Sciences. 2021 Apr 27.

29- Patil S. Potential Application of an Aqueous Extract of Tinospora Cordifolia (Thunb.) Miers (Giloy) in Oral Submucous Fibrosis-An In Vitro Study. Materials. 2021 Jan;14(12):3374.

30- Ghareeb OA. Pathological Changes in Liver Function Induced by Gold Nanoparticles and Protective Role of Tinospora Cordifolia: In Vivo. Annals of the Romanian Society for Cell Biology. 2021 Jan 31:660-5. 